\title{
A informação de proximidade no jornalismo on-line
}

Suzana Barbosa*

\section{RESUMO}

Nos sete anos de jornalismo online no Brasil, alguns formatos foram gerados para adaptar o gênero jornalistico ao suporte digital. O presente trabalho pretende enfocar o aspecto local da informação no ambiente comunicacional que é a Internet, identificando algumas experiências para além das ediçōes online de jornais diários com similares impressos. que se apropriam das redes telemáticas para distribuir conteúdos originais direcionados. Os conceitos de globalização, localização e glocalização são abordados para apontar como o jornalismo pode utilizar as ferramentas da mundialização para a informaçāo de proximidade. Este artigo integra a pesquisa em desenvolvimento no mestrado sobre o jornalismo online em portais locais.

\section{ABSTRACT}

In seven years of online journalism in Brazil, some formats had been created to adapt the journalistic genre to digital support. The current article intends to focus on the local aspect of information in the communicational environment, which is the Internet, identifying similar experiences - beyond online issues which have similar printed versions. that appropriate from telematic networks to distribute original directed contents. The concepts of globalization, localization and glocalization have been used to express how journalism can use the tools of mundialization for information of proximity. This article is part of a research which has been developed in the master course about online journalism in local portals.

*Jornalista. Mestranda em Comunicação e Cultura Contemporāneas, Faculdade de Comunicação. Universidade Federal da Bahia - FACOM/UFBA. Bolsista Capes. E-mail: suzana-bar uol.com.br 


\section{Introdução}

Na década de 90, o filósofo Michel Serres já afirmava que a nossa relação com o mundo mudara. Diversamente ao que ocorria anteriormente, quando se tinha uma relação "local-local", agora era "local-global", pois, dizia ele, através dos satélites podíamos ter imagens da terra absolutamente inteiras. Muito mais próximos de nós do que os satélites a nos fornecer imagens do planeta, e possibilitando conexões mais interativas que a televisão, os computadores com acesso à Internet permitem-nos viver essa relação local-global de maneira ainda mais próxima e 24 sobre 24 horas. O funcionamento segundo uma lógica descentralizada faz com que as informações circulem num fluxo ininterrupto pela Grande Rede abarcando cada vez mais pessoas em suas malhas que a partir das suas localidades se integram num movimento em direção ao universal que, na cibercultura, se articula com a idéia de não totalização. Pois, como escreve Pierre Lévy, tratase de um universal acompanhado de todas as ressonâncias possíveis, uma vez que possui uma relação profunda com a idéia de humanidade. "Cada conexão suplementar acrescenta ainda mais heterogeneidade, novas fontes de informação, novas linhas de fuga, a tal ponto que o sentido global encontra-se cada vez mais perceptivel, cada vez mais difícil de circunscrever, de fechar, de dominar" (Lévy, 1999, pp:120).

A Internet reflete a diversidade da humanidade e seu funcionamento descentralizado permite usos e apropriações variadas a circulação de diversas vozes. No que concerne ao jornalismo online - a quarta espécie do jornalismo, como se referem Jo Bardoel e Mark Deuze (1999) - as experiências e modelos geraram uma diferenciação de formatos que contemplam a distribuição de conteúdos variados, a depender do perfil da publicação. Assim, temos, além das edições online dos jornais comerciais, diários e com similares impressos, os grandes portais, agregando informação jornalística abrangente, serviços e entretenimento, e os portais locais ou regionais - sites com atuação focada em um determinado estado ou uma cidade, que se concentram na oferta de conteúdo local e serviços específicos.

Esses portais trabalham na veiculação de informação local, que, segundo apontam algumas pesquisas nos Estados Unidos, é um tipo de conteúdo com grande demanda na rede. Nos EUA, aproximadamente 48 milhões dos usuários adultos ${ }^{1}$ procuram sites que forneçam informação local. No Brasil, ainda não há números específicos, embora possamos 
considerar crescente o número de sites focados nessa área. A informação de proximidade não é exclusiva dos portais regionais ou locais, já que é possível encontrar esse tipo de conteúdo nas edições online dos jornais, embora estes limitem a cobertura ao que é noticiado pela versão impressa, além de notas nas seções de "últimas notícias", mas ainda assim de forma pouco dinâmica. Tem-se. ainda. os guias urbanos de cidade que ofertam serviços de lazer e entretenimento.

Neste artigo, o foco principal está no aspecto local da informação. Assim, identificamos algumas experiências que têm dado ênfase aos conteúdos locais, aplicando os conccitos de produção através das redes telemáticas para distribuir informações originais e direcionadas. Apresentamos as características identificadas nos portais regionais ou locais e também abordamos o jornalismo de portal como sendo uma categoria do jornalismo na Internet. Discorremos, ainda. sobre os momentos de diferenciação no jomalismo online. cujas primeiras experiências foram iniciadas ainda nos anos 80 por alguns jornais dos Estados Unidos a partir da comercialização de resumos selecionados de seus produtos para assinantes com aparelhos de fax (Squirra, 1997; Dizard Jr., 2000)).

\section{Diferenciação de formatos}

Quando os primeiros jornais comerciais diários norteamericanos começam a migrar para o suporte digital - o que ocorre a partir de 1994 com o San Jose Mercury Newrs - a transposição dos contcúdos da edição em papel para a edição online é o modelo que impera. Era uma transferência simples de conteúdo do jornal para o ambiente digital, num momento em que os recursos e potencialidades do meio eram desconhecidos ou ignorados (Alves, 2001, p.4) e a metáfora do jornal impresso passa a ser adotada no jomalismo online. seja na linguagem, na divisão por editorias, na forma de apresentação das telas principais dos sites (como se fosse a primeira página de um jornal) e na própria utilização da palavra "jornal".

A transposição é o modelo de jornalismo online correspondente à fase inicial de expansão da World Wide Web (WWW). que no Brasil se dá a partir de 1995 com a liberação do acesso comercial e a operação de provedores, coincidindo com o lançamento da primeira edição completa de um jornal nacional na Internet - o Jornal do Brasil www.jb.com.br. Após a euforia da estréia na Rede, os grupos editoriais. assim corno as empresas jornalísticas. perceberam que para seus 
respectivos sites terem visibilidade precisariam ser acessados e, para isso, era necessário ofertar conteúdos exclusivos para além daquele disponível nas edições impressas, implementando canais de notícias em "tempo real" para despertar e criar o hábito da leitura da versão online. Atualmente, no Brasil, apesar da evolução dos modelos, muitos jornais ainda estão operando segundo o formato transpositivo, conforme avaliou a pesquisa Um mapeamento de características e tendências no jornalismo online brasileiro, financiada pelo Pibic e realizada entre agosto de 2000 e agosto de 2001 pelo Grupo de Jornalismo Online da Faculdade de Comunicação da UFBA ${ }^{2}$.

Num período considerado curto, um ano e meio depois da estréia dos grandes jornais brasileiros na Web - entre 1996/1997 - começam a surgir na Internet brasileira produtos criados especificamente para o suporte digital $^{3}$, sem similares no meio impresso e operando de maneira mais afinada com o ambiente digital no que se refere à publicação de conteúdos mais interativos, com circulação personalizada, e contextualizados com os recursos multimídia, e da própria escrita hipertextual, marcada pela supressão de limites de espaço e de tempo e tendo o link ${ }^{4}$ como o elemento constitutivo e inovador para o hipertexto digital.

Um novo momento de diferenciação para o jornalismo online vai acontecer com a ascensão dos portais - páginas que centralizam informações gerais e especializadas, serviços de e-mail, canais de chat $\mathrm{e}$ relacionamento, shoppings virtuais, mecanismos de busca na Web, entre outros, e cuja intenção é ser a porta principal de acesso a orientar a navegação do usuário pela WWW. Foram os americanos que criaram e batizaram esses sites de "portais"s. No Brasil, o ano de adoção desse modelo e também do próprio conceito de portal foi 1998. Atualmente, entre os grandes portais operando no Brasil estão o UOL (www.uol.com.br), Terra (www.terra.com.br), iG (www.ig.com.br), America Online/AOL (www.aol.com.br), Globo.com (www.globo.com.br) e Yahoo (www.yahoo.com.br).

José Afonso Silva Jr, aponta três fatores para a diferenciação entre os sites de jornais online - geralmente com similares impressos de portais jornalísticos online, quais sejam: agregação de serviços paralelos ao caráter informativo, de natureza não necessariamente jornalística; a inter-relação estabelecida com sites de conteúdo diverso, no sentido de fornecimento de informações jornalísticas, inclusive por agências; e a convergência, em alguns casos, do serviço de provedor de acesso com o de disponibilização de conteúdo. (Silva Jr.,2000, pp: 
80). Os portais, de fato, produziram uma categoria para o jornalismo online: o jornalismo de portal, marcado por uma dinâmica mais ágil, principalmente pela consolidação do modelo de notícias em tempo real. as chamadas hard news, bem próximas do formato de conteúdos gerados pelos canais de notícias 24 horas das redes de TV a cabo. como CNN, Globo News, Band News.

A pesquisa que mapeou as tendências do jomalismo online brasileiro também aferiu que é nos portais onde se encontra um jornalismo mais diferenciado, pois neles se observa novos recursos incorporados à veiculação de notícias, como por exemplo os boletins que integram TV e Web num modelo híbrido do "ao vivo" com "últimas notícias", como o UOL News, com Paulo Henrique Amorim no portal UOL, c o Jornal da Lillian, com Lillian Witte Fibe. no Terra (Aranha, p: 70). Ambos são serviços oferecidos aos assinantes que têm acesso Internet via banda larga, embora os demais usuários possam acessálos só no modelo texto.

Além dos "canais" de últimas notícias. os mega portais como UOL, têm como parte integrante do seu conteúdo os sites de grandes jornais consolidados na mídia impressa. os quais. por sua vez. lambém possuem equipes atualizando o conteúdo de suas respectivas versões online ao longo do dia. Estar num grande portal significa maior visibilidade para jornais, inclusive regionais, a exemplo do Jornal do Commércio do Recife, ou até mesmo "A Região", de Itabuna (Bahia), ambos hospedados no UOL. Um dos aspectos negativos do modelo de portal é que, neles, o jornalismo está colocado como mais um produto, disputando a atenção do usuário, ainda que, na maioria dos casos. ele seja o carro-chefe, a exemplo do jornal último Segundo. do portal iG. "(...) O portal constitui-se numa poderosa variante de publicisação de conterido na Internet, no sentido de ao mesmo tempo procurar ama maior permanência do usuário dentro de determinado site, eagregar a essa possícel navegação do usuário, uma miriade de serviģos que antes, senão impensada, era improvível de ser executada com eficiência técnica". (Silva Jr.. 2000, p: 80)

A oferta casada de informação (banco de dados, hipertextos. áudio, vídeo), serviços, entretenimento e produtos num só lugar além de gerar volume de acessos, aumentando a audiência. é o ponto de partida para se atrair os usuários. Ihes permitindo participar de uma comunidade não apenas existente no ambiente eletrônico mas com suas ramificações no espaço físico das cidades. O modelo dos portais 
pode ser uma alternativa ou esperança para o excesso de informações disponíveis na rede, atuando como intermediários, mediadores. Filtram e permitem encontrar (Vaz, 2000, p: 12). Por outro lado, os chamados portais também constituem um modelo que padroniza, uniformizando fontes e conteúdos, e até mesmo o design, reforçando muito mais a homogeneidade na Rede. Ademais, os portais - que, suspeitamos, ainda serão um modelo válido por um bom tempo - são criticados pela sua pretensa solução para o excesso informacional.

"Embora busquem agregar supostos conteúdos importantes, os portais nos tiram, enquanto fenômeno hegemônico a possibilidade de crrância, da ciberflânerie, nos transformando em surfers-bois, marcados pelo ferro do ebusiness. Devemos reverter a hegemonia e a população desta nova prisão eletrônica que se configura com a atual onda dos portais-currais". (Lemos, 2000, p: 02).

Para Camargo e Becker (1999), os portais são inevitáveis (e úteis) por um lado, pois ninguém consegue ler tudo o que é colocado na Web. No entanto, por outro lado, conforme afirmam, a brutal supressão da diversidade de fontes de informação e o consequiente direcionamento da ação de tomar conhecimento de alguns em detrimento de outros fatos, de alguns aspectos da realidade e não de outros, de apenas uma versão, perspectiva ou razão de um dado acontecimento, torna os habitantes do planeta um pouco menos cidadãos a cada dia (Camargo e Becker, 1999, p: 16).

Diante disso há que se considerar que, embora o conteúdo a ser veiculado nos portais pressuponha uma seleção e definição prévias das fontes de notícias e dos demais produtos e serviços a serem ofertados, pela primeira vez o público tem à sua disposição uma diversidade de canais de notícias, advindas de diferentes fontes num só lugar (ainda que as grandes agências de notícias sejam as principais distribuidoras de conteúdo para os canais de "últimas notícias", de certa forma homogeneizando a informação nos diferentes portais, que podem, se assim quiserem, dar tratamento diferenciado ao material).

Acreditamos que, por mais hegemônico que pareça ser o modelo dos portais, a visibilidade deles na Internet não tira do usuário/ internauta o poder de exercer a errância, a navegação livre ou experimentar as sensações de um flâneur ${ }^{6}$. No que concerne ao jornalismo online, os mega portais vão abrir caminho para o surgimento de uma outra modalidade - os portais locais, que se concentram na oferta de conteúdo e serviços direcionados a uma localidade específica. 
Os portais locais ou regionais são uma nova categoria para o jornalismo online, pois cumprem a função de usar a informação segundo os critérios de proximidade, veiculando-a em consonância com as características do jomalismo online: interatividade. hipentextualidade. multimidialidade, personalização e memória. Os portais locais começaram a ser difundidos no Brasil a partir de 1999. sendo mais um modelo importado da Web norte-americana e que também foi replicado $\mathrm{em}$ vários países.

Os espaços da globalização são espaços mundializados reunidos por redes (Santos, 1996, p: 268). Estas, por sua vez, são globais e transportam o universal ao local, unindo pontos distantes numa mesma lógica produtiva. Nesse contexto, muitos acreditam que há uma homogeneização ameaçadora das identidades nacionais. assertiva combatida por Stuart Hall, entre outros pensadores. Hall observa que. ao lado da tendência em direção à homogeneização, há uma fascinação com a diferença e com a mercantilização da etnia e da alteridade. ao passo que há, juntamente com o impacto "global". un novo interesse pelo "local".

\section{Novo interesse pelo local}

Os espaços da globalização são espaços mundializados reunidos por redes (Santos, 1996, p: 268). Estas, por sua vez, são globais e transportam o universal ao local, unindo pontos distantes numa mesma lógica produtiva. Nesse contexto, muitos acreditam que há uma homogeneização ameaçadora das identidades nacionais. assertiva combatida por Stuart Hall. entre outros pensadores. Hall observa que. ao lado da tendência em direção à homogeneização. há uma fascinação com a diferença e com a mercantilização da etnia e da alteridade. ao passo que há, juntamente com o impacto "global". um novo interesse pelo "local".

"A globalização (na forma da especialização flexirel e da estratégia de criação de "nichos" de mercado), na verdade. explora a diferenciaçäo local. Assim, ao invés de pensar no global como "substituindo" olocal seria mais acurado pensar muma nova articulação entre "o global" e "o local". (Hall, 2001, p: 77).

Esta articulação coloca o local no interior da lógica da globalização (um fenômeno ocidental) que. provavelmente. em vez de destruir as identidades nacionais, poderá produzir novas identificações "globais" e novas identificações "locais". Afinal. cada lugar é. à sua 
maneira, o mundo, que se encontra em toda parte. Milton Santos (1996, p: 252) diz que a uma maior globalidade, corresponde uma maior individualidade, fenômeno denominado como "glocalidade" por Georges Benko (apud Santos, 1996, p: 65). Assim, o local se constitui como espaço privilegiado onde é fundada a escala do cotidiano e onde novas formas de sociabilidade e também de socialidade ${ }^{7}$ são engendradas. Enquanto a ordem global é "desterritorializada", separando o centro da ação e a sede da ação e dependente de fatores externos, a ordem local "reterritorializa", reunindo em sua lógica interna todos os elementos: homens, empresas, instituições, formas sociais. Dessa maneira, é no âmbito local onde a cultura global hegemônica é refuncionalizada através de relações de assimilação e rejeição, constituindo no que o sociólogo inglês Roland Robertson classifica de "glocalização"8 processo de interação entre o local e o global e vice-versa, mistura de globalização com características locais.

Estas considerações ajudam na compreensão da importância que adquire o local na contemporaneidade, em plena vigência da globalização. Ao lado disso, percebe-se que também no jornalismo online, o aspecto local vem sendo privilegiado, refletindo uma contiguiidade com essa realidade expressa no espaço territorial. Afinal, o discurso jornalístico é 54 uma modalidade de transmissão do conhecimento da realidade e, como tal, na contemporaneidade, usa a estrutura do ambiente digital e das redes telemáticas para a veiculação de conteúdos localizados.

Os sites com conteúdos locais - sejam de jornais, portais, guias urbanos e demais serviços - são uma tendência crescente na Internet e atuam também no sentido de despertar o interesse da comunidade para o uso da Rede, criando vínculos de pertencimento pela proximidade, pois é ela que pode criar "solidariedade, laços culturais e desse modo identidade" (Santos, 1996, p: 255). Na Internet, cada vez mais, iniciativas são direcionadas para expressar e fazer circular conteúdos, serviços e bancos de dados focados no interesse das comunidades, refletindo a sua identidade. O que, de fato, constitui uma das vocações dos jornalismo online, como observa Zélia L. Adghirni.

"Os internautas se conectam muito mais para saber o que se passa no seu bairro, na sua cidade, do que no resto do mundo (...) Enquanto as tecnologias de comunicação precedentes valorizavam a informação global, o webjornalismo privilegia o local". (Adghirni, 2001, p: 9)

Grandes jornais como o Washington Post (www.washingtonpost.com), o New York Times (www.nytimes.com) e 
o Chicago Tribune (www.chicagotribune.com) têm espaços dedicados à cobertura local e à publicação de conteúdos direcionados à própria cidade onde estão baseados, assim como às regiões próximas às suas respectivas sedes. O Chicago Tribune Internet Edition possui equipe que cobre notícias urgentes na região de Chicago, disponibilizando, ainda, a seção Day Watch que envia as notícias locais por e-mail aos assinantes do serviço. Na França, há sites institucionais das administrações regionais de pequenas localidades que também incorporaram a Internet em sua comunicação com os cidadãos através de sites com conteúdos direcionados. Além disso, existem os guias locais urbanos, inspirados no modelo norte-americano, que chegaram à França em 1998. Eles trabalham com equipes baseadas nas principais cidades do país para produzir conteúdos de serviços, agenda cultural, entre outros. Alguns deles são o Webcity.com (www.webcity.com), Maville.com (www.maville.com), o Vivaville.com (www.vivaville.com), Viapolis.com (www.viapolis.com) e o Paris-avenue.com (www.paris-avenue.com).

Na Espanha, desde 1995, a experiência catalã Vila Web (www.vilaweb.com), criada originalmente com o nome La Infopista para ser um diretório local independente reunindo sites web em língua catalã. se distingue pelo modelo adotado. Na Vila Web, os jornalistas trabalham nãoexplicando notícias, mas indicando onde elas são produzidas, oferecendo variadas versões de uma história para situar o leitor em relação às fontes. "Procuramos a notícia e damos ao leitor os meios de interpretá-las", explica Vicent Partal, um dos sócios-fundadores da Vila Web.

O conceito no qual se baseia a Vila Web é utilizar as ferramentas tecnológicas e as redes telemáticas para a informação de proximidade. "Integramo-nos na globalização para contribuir com a nossa observação - nem melhor nem pior, simplesmente diferente" (Partal, 1998). A Vila Web disponibiliza, ainda, edições locais cobrindo toda a Espanha e também outras cidades em diversos países, visando atender à comunidade catalã que vive nesses lugares, numa atuação que visa aproximar o site dos usuários não se limitando assim ao país de origem. Cada edição local está a cargo de uma empresa específica. O site informa também sobre os principais acontecimentos no mundo. A idéia dos criadores da Vila Web é construir um projeto jornalístico global (numa espécie de rede glocal) partindo da localidade e sendo uma alternativa aos meios globais.

No Brasil, os conteúdos locais são distribuídos por guias urbanos, que privilegiam informações culturais, de turismo, serviços e entretenimento, como o GuiaSP (www.guiasp.com.br) e o GuiaRio (www.guiario.com.br). 
Alguns são projetos nacionais financiados por grupos brasileiros, mas há os guias de empresas estrangeiras, como o espanhol Lanetro (www.lanetro.com) que tem atuação em diversos países e, no Brasil, oferta conteúdo direcionado a diversas cidades, como Salvador, São Paulo e Porto Alegre, conservando o mesmo perfil editorial.

$\mathrm{Na}$ lacuna deixada pelas edições online dos grandes jornais comerciais diários brasileiros, os portais locais ou regionais nos parece os que mais tem conseguido usar as características das redes telemáticas para a cobertura local, privilegiando a informação direcionada, produzida e distribuída segundo as características do jornalismo online para atrair os usuários de determinadas cidades e estados. Eles facilitam o acesso a conteúdos originais e interativos, que contemplam notícias e reportagens em geral sobre cidade, turismo, cultura, esportes, lazer, serviços, entretenimento e diversão, intensificando, ao mesmo tempo, os laços sociais e o sentimento de pertencimento a uma comunidade.

Com equipes estruturadas, das quais fazem parte jornalistas, webdesigners, profissionais da área de marketing, entre outros, os portais locais ou regionais convivem sem concorrer com os mega portais ou portais genéricos - em alguns casos até fornecem conteúdo em área específica para eles. A linguagem é híbrida, mesclando o jornalismo diário (fornecem os canais de últimas notícias) com o semanal (pois muitas matérias têm uma permanência maior no ar, o que se aproxima do jornalismo semanal, de revista), no que pode ser visto como mais uma metáfora com o meio impresso até porque as seções também estão divididas segundo editorias/canais (cidade, turismo, esporte, lazer, por exemplo). Esses portais agregam, ainda, sites independentes específicos (aqueles com conteúdos verticalizados) sobre jogos, saúde, venda de ingressos para shows e teatro, entre outros.

Três iniciativas brasileiras exemplificam bastante o fenômeno: o Uai, de Minas Gerais (www.uai.com.br), o Pernambuco.com, de Pernambuco (www.pernambuco.com.br) e o iBahia (www.ibahia.com.br) com atuação focada no mercado de Salvador. O conteúdo - o maior fator em seduzir leitores (Carole Rich, 1998, p: 03) - está em contínua atualização, sem, necessariamente, estar atrelado a horários estabelecidos. A sua formatação compreende desde as notas curtas veiculadas através dos canais de "últimas notícias", as chamadas para alimentar a seção WAP, bem como as matérias que têm maior permanência no ar, até os bancos de dados com informações 
classificadas como de "utilidade" e. ainda, através de especiais temáticos.

\section{Portais locais em estudo}

Três iniciativas brasileiras exemplificam bastante ofenômeno: o Uai, de Minas Gerais (www.uai.com.br). o Pernambuco.com, de Pernambuco (www.pernambuco.combr) e o iBahia (www.ibahia.com.br) com atuação focada no mercado de Salvador. O conteúdo - o maior fator em seduzir leitores (Carole Rich, 1998, p: 03) - está em contínua atualização, sem, necessariamente. estar atrelado a horários estabelecidos. A sua formatação compreende desde as notas curtas veiculadas através dos canais de "últimas notícias", as chamadas para alimentar a seção WAP, bem como as matérias que têm maior permanência no ar, até os bancos de dados com informações classificadas como de "utilidade"e, ainda, através de especiais temáticos.

Analisando os três portais. percebe-se que no Uai - o primeiro portal regional do país - e no Pernambuco.com existe uma maior produção de conteúdos jornalísticos. enquanto o iBahia (ligado à Rede Bahia) se concentra mais na oferta de conteúdo para os canais de entretenimento, diversão e serviços. As informações sobre o que acontece na cidade, no Brasil e mesmo em outros países estão tratadas nas "últimas notícias", cuja seção no iBahia é denominada "Plantão $i "$. A produção dessa área do site também é veiculada através do portal Globo.com quando o assunto é considerado relevante pela equipe do mega portal das Organizações Globo. do qual o iBahia é parceiro. Por outro lado, toda a produção de notícias nacionais e internacionais para o "Plantão i" é gerada apenas pelo Globo.com. O iBahia, ao contrário do Uai e Pernambuco.com, não possui contrato direto com agências de notícias para divulgação de seus conteúdos.

O site veicula matérias do Correio da Bahia. pertencente ao mesmo grupo empresarial, mas, ainda assim. utiliza esse conteúdo local em suas páginas de forma limitada. Un exemplo que se pode apontar é o da morte do escritor Jorge Amado. Em vez de dedicar cobertura mais ampla sobre o fato, valendo-se, inclusive. do caderno especial editado pelo jornal impresso, o iBahia se resumiu a notas no "Plantão i”. quando poderia ter trabalhado através do recurso de blocos de texto com a linkagem do material especial produzido pela editoria de cultura do Correio da Bahia ou com as reportagens da editoria de Cidades (Aqui Salvador). Perdeu a oportunidade de ser referenciado nacionalmente e, assim, ampliar a sua audiência, o que, de acordo com Steve Outing. se configura num erro, 
pois, ainda que o site local seja apenas um guia (que não é o caso do iBahia), ele tem que entender o seu posicionamento estratégico e tirar partido da situação privilegiada de estar firmado no lugar onde o fato ocorre para realizar uma boa cobertura. Por sua vez, os portais Pernambuco.com e Uai foram além das "notinhas" e veicularam matérias dando conta da morte do escritor com material de agências de notícias que foi redigido por suas equipes.

Com formatos de matérias que têm tamanho variado, com três, quatro, seis ou mais parágrafos, a depender do assunto, os portais privilegiam o texto objetivo, claro, conciso e a técnica da pirâmide invertida, baseada na hierarquização dos fatos, para a redação. Entre os recursos mais utilizados estão fotografias, simulações e, em alguns casos, vídeos. Os links são intertextuais e intratextuais. Dos três portais, apenas o Uai agrega o serviço de provimento de acesso ao de conteúdo e, por isso, há algumas partes do site que são fechadas aos assinantes do provedor homônimo. Seguindo uma tendência dos grandes portais e dos sites dos jornais, os portais locais também disponibilizam especiais com cobertura sobre determinado acontecimento, como o seqüestro de Patrícia Abravanel, filha do empresário Silvio Santos e a invasão à sua casa (ocorridos em agosto de 2001), e os ataques terroristas em Nova York e Washington, em 11 de 58 setembro do mesmo ano.

Em ambos os casos, o tratamento das informações variou de um portal para o outro. Os três portais se preocuparam em trazer para os usuários das cidades aonde estão baseados os acontecimentos que mobilizaram o país e o mundo. O Uai foi além, e também trabalhou a contextualização local para o caso dos atentados, mostrando as consequiências em alguns setores e repercutindo a situação no estado. É importante notar que a oferta de conteúdo e o tratamento dado às informações estão mais afinados com as características do JOL e os recursos do meio nos sites onde as equipes são mais bem estruturadas e parece haver melhor entendimento sobre os procedimentos de produção nas redes. O Uai e o Pernambuco.com, por exemplo, colocaram especiais sobre o "terror nos EUA" no mesmo dia, com boa quantidade de fotos, textos e a contextualização da informação, implementando o conteúdo nos dias seguintes. $\mathrm{O}$ iBahia se concentrou nas notas e nas fotos enviadas pelo Globo.com. Alguns dias depois, o site abriu espaço em sua área para o especial "Terrorismo", que linkava para o portal Globo.com, disponibilizando, ainda, imagens de Nova York antes do atentado feitas por webcams posicionadas numa das torres do World Trade Center. 
No que se refere à arquitetura da informação, os três sites apresentam design que favorece a visibilidade, permitindo localizar os conteúdos com facilidade. O design, de certa maneira, segue a tendência inaugurada pelos megaportais, com a área do site dividida em três partes, sendo a esquerda para a apresentação dos canais, a parte central para as chamadas principais incluindo as notícias atualizadas instantaneamente, e a do lado direito para os canais de compra (no caso do Pernambuco.com) e outras informações e serviços. As possibilidades de interação com o leitor/usuário nesses sites são percebidas através do envio de e-mails direto à redação e também por meio da opção de "comente esta matéria". Os três permitem enviar conteúdos diretamente por e-mail. Quanto à fidelização do usuário. a estratégia dos portais locais analisados vai na mesma direção, com sorteio de brindes e convites para festas e shows, o que é, em nossa avaliação, apenas uma possibilidade entre outras que se pode utilizar; como cartões que ofereçam descontos em estabelecimentos das respectivas cidades (envolvendo assim empresas dos mais diversos setores de atuação), além de promoção de eventos para reunir usuários dos sites. Desta maneira, os elos se estenderiam também ao território, às cidades, constituindo espaço de relação na sociedade e intensificando os níveis de identificação dos usuários/leitores com o portal.

Nos portais locais vale o princípio da proximidade da informação com determinado público e esse formato. conforme Steve Outing (1999). é uma estratégia inteligente para a Web que o setor jornalístico aceitou. Ele aponta alguns serviços que esses portais devem oferecer para obter sucesso, tais como: sistema de busca por tópicos, sistema de manchetes do dia, seção de fóruns e debates sobre diversos temas, links atualizados para os principais jornais, revistas e sites de notícias, links para serviços diversos (eventos, programação cultural, entre outros), salas de bate papo, relações de compras online, serviço personalizado de home page e serviço gratuito de webmail. Nos portais locais analisados vê-se a oferta de boa parte desses serviços, tais como a busca por tópico, links para eventos, programação cultural, chat, e e-mail gratuito, links para jornais (o Uai disponibiliza em seu site todas as publicações pertencentes à cadeia Diários Associados em Minas Gerais, entre elas o jomal Estado de Minas; o Pernambuco.com disponibiliza o conteúdo do Diário de Pernambuco, ambos integrantes da rede Diários Associados). Já o iBahia apenas ocasionalmente referencia o conteúdo produzido pelas editorias do Correio da Bahia. Também não dispõe de seção específica com links para jornais, 
revistas ou outros sites noticiosos. O conteúdo está ancorado na própria produção por parte da sua equipe e no de sites verticalizados parceiros do portal. Quanto aos serviços de compras online, o Pernambuco.com oferece melhores possibilidades, já que tem o Submarino como um dos principais canais para o comércio eletrônico agregados ao portal. No iBahia, é possível comprar ingressos para shows através do canal "Pida".

Os portais estão constantemente sendo alimentados com informações jornalísticas e de entretenimento e, conforme os seus responsáveis, eles, de fato, atendem aos interesses dos usuários. "Acredito que quanto mais global for o meio de comunicação maior será o interesse pelo local. As pessoas querem saber o que acontece na sua comunidade e vão buscar todos os meios para obter estas informações", afirma o superintendente do Uai, Geraldo Teixeira da Costa Neto9.

Para a gerente de Internet do Pernambuco.com, Silvia Valladares, ninguém vai fornecer informação local tão bem quanto um grupo de mídia local.

"Impossivel o UOL saber tanto de Pernambuco quanto o Pernambuco.com. É uma questão até mesmo física que importa nesta hora. Então, existe uma oportunidade nisso. No quesito notícias, serviços, guias, qualquer portal regional, desde que tenha qualidade, é imbativel para seu público. Os grandes nacionais estão definidos, mas ainda há espaço para os pequenos".

Para a editora do iBahia, Márcia Luz, na Internet a necessidade da informação de proximidade é muito mais importante e, no caso dos portais locais ou regionais, eles devem fazer com que o usuário sinta que tudo nele é feito para atendê-lo, senão, muito pouco valor terá o trabalho de regionalização e de prestação de serviço.

"Embora o mundo inteiro fale em globalização, este é o fator que faz a diferença no jornalismo da lnternet. Na verdade, nada mais é do que uma repetição do jornalismo feito no impresso, o de televisão e o de rádio, porque a população de um bairro, cidade ou estado quer saber o que está acontecendo no seu diaa-dia". ${ }^{11}$

\section{Algumas considerações}

Constituindo-se como um dos formatos para o emergente jornalismo online, os portais locais ou regionais, diferentemente das edições online dos jornais diários comerciais, neste momento, trabalham muito mais a informação de proximidade como um dos diferenciais para despertar a atenção e a audiência do usuário, sendo também uma iniciativa clara de percepção do uso das novas tecnologias para 
aproximar-se das comunidades e. ao mesmo tempo, socializar a apropriação dessas tecnologias. E, para isso, os conteúdos privilegiam também a oferta de serviços (condições do trânsito. banco de dados com os CEPs de ruas, locais para tirar documentos, elc) que, em geral, as edições dos grandes jornais não demonstram muito interesse. Eles também recuperam a memória tanto no nível do produtor da informação como do usuário, já que com a Internet - e o jornalismo online - esta capacidade é ampliada.

Sobre o jornalismo ligado a serviços. Bardoel e Deuze atestam: "O jornalismo tornará uma profissão que fornece serviços. não a coletivos, mas, primeiro, aos indivíduos. e não unicamente em sua capacidade como cidadãos, mas também como consumidores. empregados e clientes" (Bardoel \& Deuze, 1999, p: ()8).

Ao que se pode acrescentar que. desta maneira. aumenta em grande medida a responsabilidade dos profissionais em fazer um jornalismo de serviço com conteúdo original. dirigido a uma determinada localidade. Sem esquecer que o jornalismo online como método singular de interpretação do presente social (Machado, 2000, p: 9) também estende suas potencialidades para organizar a inteligência coletiva e a própria memória nas redes digitais. Os sites com conteúdos locais podem ser. inclusive. uma refutação à representação da Rede como destruidora da sociabilidade (Sassen, 2000), ao mesmo tempo em que constituem uma alternativa à homogeneidade, dando forma ao web-urbanismo. Assim, conforma-se um global como resultado da multiplicação do local.

\section{Referências bibliográficas consultadas:}

ADGHIRNI, Zélia Leal e RIBEIRO. Gilseno de Souza Nunes. Jornalismo online e identidade profissional do jornalista. Brasília. maio/2001. Acesso: via e-mail.

ALVES, Rosental. Reiventando o jornal na Internet - A internet: chegou a hora de reavaliar sua funçäo no jornal impresso. Austin/ Texas (EUA)/Fortaleza (Brasil). março/2001. Acesso: via e-mail. ARANHA, Patrícia. A televigilancia do acontecimento. Anćlise da notícia em tempo real (dissertação de mestrado). Faculdade de Filosofia e Ciências Humanas, UFMG, junho/2001.

BARDOEL, Jo \& DEUZE, Mark. Network Journalism. Capturado em 13 out. 2000. Online. Disponível na Internet

BASTOS, Hélder. Do jornalismo online ao ciberjornalismo: 
emergência de novas práticas nos media portugueses. In: TRAQUINA, Nelson (org.). Revista de Comunicação e Linguagens. 27, Lisboa: Ed: Relógio D'Água, fev. 2000.

CAMARGO, Nelly de. e BECKER, Maria Lúcia. Dos portais à grande muralha. In Revista Contato, $\mathrm{n}^{\circ} 3$, abril/junho/99

DIAS, Cláudia Augusto. Portal corporativo: conceitos e características. Revista Ciência da Informação, v. 30, n.1. jan/abr/2001.

EVANS, Fred. Cyberspace and the concept of democracy. Capturado em 15 dez. 2000. Online. Disponivel na Internet

GONÇALVES, Elias Machado. La Estructura de la Noticia en Las Redes Digitales. (Un estudio de las consecuencias de las metamorfosis teecnológicas en el periodismo). (Tese de Doutorado), Facultad de Ciencias de la Comunicación/Universidad Autónoma de Barcelona, 2000.

GONÇALVES, Elias Machado e PALACIOS, Marcos. Manual de Jornalismo Digital, Salvador, FACOM/UFBA, 1996. Disquete. 1 disquete 31/2. Para uso em PC.

HALL, Stuart. A identidade cultural na pós-modernidade. Rio de Janeiro: 5.ed. DP\&A, 2001.

JÚNIOR, Wilson Dizard. A nova mídia - a comunicação de massa na era da informação. Rio de Janeiro. Jorge Zahar, 2000.

62 KRASILOVSKY, Peter. Local online advertising: market and players. Relatório elaborado para o The Interactive Advertising Bureau. Oakton (EUA), maio 2001. Acesso: via e-mail.

LEMOS, André. Morte aos Portais. Capturado em 16 out. 2000. Online. Disponível na Internet

LÉVY, Pierre. Cibercultura, São Paulo: Ed. 34, 1999.

MIELNICZUK, Luciana; PALÁCIOS, Marcos. Considerações para um estudo sobre o formato da notícia na Web: o link como elemento paratextual. FACOM/UFBA, 2001.

MOHERDAUI, Luciana. Guia de estilo Web - Produção e edição de notícias online. São Paulo, Ed. Senac. 2000.

OUTING, Steve. Estratégia para portais regionais. Capturado em 13 out. 2000. Online. Disponível na Internet

Jornais locais e a busca por uma audiência mais ampla. Capturado em 26/07/01. Online. Disponível na Internet

PALACIOS, Marcos. O que há de (realmente) novo no Jornalismo online? Seminário proferido na FACOM/UFBA, 04/04/2000. 
PARTAL, Vicent. Jormalismo glocal: utilizando as ferramentas da globalidade para a informação de proximidade. Capturado em 25/ 07/01. Online. Disponivel na Internet

RICH, Carole. Redação Jomalística para a Web: Um estudo para o Instituto Poynter de Estudos de Mília. Tradução José Antônio Meira. Porto Alegre: Agência Experimental de Jornalismo da Unisinos, (1998). Título original: Newswriting for the web. A study for The Povnter Institute of Media Studies.

SANTOS, Milton. A natureza do espaço: técnica e tempo - razão e emoção. São Paulo. Ed. Hucitec, 1996.

SASSEN, Saskia. Web-urbanismo. In. Hypertexto, primeira edição, 31/10/00. Capturado em 18/01/01. Online. Disponivel na Internet

SIMONE, José Fernando; MONTEIRO, Mariana. Jornalismo online O futuro da informação. Webmeio Edições, Rio de Janeiro, 2001.

SILVA JR. José Afonso. Jomalismo 1.2: características e usos da hipermídia no jornalismo, com estudo de caso do Grupo Estado de São Paulo. Salvador, 2000. Dissertação (Mestrado em Comunicação e Cultura Contemporâneas), Faculdade de Comunicação, UFBA, 2000. Disquete. 1 disquete 31/2. Para uso em PC.

SILVA, Luis Martins da. Imprensa, discurso e interatividade. In: MOUILLAUD, Maurice; PORTO, Ségio Dayrell (org.). O jornal: da forma ao sentido. Brasília: Paralelo 15, 1997.

SQUIRRA, Sebastião. Jomılismo online. São Paulo, CJEJECAJUSP, 1997. VAZ, Paulo. Esperança e excesso. Comunicação, tecnologia e sociabilidade. $9^{\circ}$ Encontro Anual da Associação Nacional de Programas de Pós-Graduação Em Comunicação. Mai/jun. 2000. Porto Alegre. CD-ROM.

\section{NOTAS}

'Dado fornecido pela CyberDialogue referenciado por Peter Krasilovsky no relatório Local online advertising: market and players (Maio/2001), elaborado para o The Interactive Advertising Bureau.

${ }^{2}$ Foram avaliadas as edições online de 44 jornais do tipo comercial e diário, de todas as regiões do país, que disponibilizam conteúdo gratuito na Internet. A seleção tomou como base as empresas jomalísticas vinculadas ao Instituto Verificador de Circulação (IVC). 
${ }^{3}$ Um exemplo é a publicação IDGNow! ( cobrindo assuntos direcionados às áreas de tecnologia, informática, internet e economia.

${ }^{4}$ Essa idéia é desenvolvida por Luciana Mielniczuk e Marcos Palácios no texto Considerações para um estudo sobre o formato da notícia na Web: o link como elemento paratextual. Eles defendem que o link é o elemento realmente inovador apresentado pelo hipertexto em suporte digital. A afirmação está calcada, principalmente, em dois motivos que estão relacionados com a característica da intertextualidade e da multimidialidade.

${ }^{5}$ Cláudia Augusto Dias (2001) afirma que o que hoje é chamado de portal era conhecido como máquina de busca, há três, quatro anos, cujo objetivo era facilitar o acesso às informações contidas em documentos espalhados pela Internet. Após a inclusão de categorias para filtrar documentos pré-configurados de acordo com seu conteúdo e da integração de outras funções, como chats e listas de discussão, é que a nova concepção de máquina de busca passou a ser chamada de portal. ${ }^{6}$ Espécie de andarilho virtual, que faz reviver a figura do flâneur, surgido nas arcadas da Paris do século XIX. Para W. Benjamin, o flâneur, andarilho observador que se move através das paisagens urbanas e das multidões, foi um fenômeno chave para entender a cidade moderna.

${ }^{7}$ Terminologia proposta por Michel Maffesoli para classificar a estrutura das relações sociais na cultura contemporânea, onde as ligações têm bases mais afetivas, presenteístas, efêmeras; ao contrário da sociabilidade, onde as formações de elos sociais são baseadas nas instituições oficiais.

${ }^{8}$ Robertson propõe a substituição do termo globalização por glocalização, pois, segundo ele, é mais preciso. Para R. Robertson, globalização envolve a simultaneidade e a interpenetração do que está sendo convencionalmente chamado de global e local ou de universal e particular. Ver, sobretudo, o capítulo "Glocalização: tempo-espaço e homogeneidade-heterogeneidade" (Robertson 2000: 246-268).

${ }^{9}$ Entrevista concedida via e-mail em 24 de setembro de 2001.

${ }^{10}$ Entrevista concedida via e-mail em 28 de setembro de 2001.

"Entrevista concedida via e-mail em 01 de outubro de 2001.

\section{Palavras-chave}

1. informação local

2. jornalismo online

3. portais locais 